\title{
Plasma rich in growth factors eye drops to treat secondary ocular surface disorders in patients with glaucoma
}

This article was published in the following Dove Press journal: International Medical Case Reports Journal

\author{
Ronald M Sánchez-Avila' \\ Jesus Merayo-Lloves' \\ Maria Laura Fernández ${ }^{1,2}$ \\ Luis Alberto \\ Rodríguez-Gutiérrez' \\ Pedro Pablo \\ Rodríguez-Calvo' \\ Andres Fernández-Vega \\ Cueto' \\ Francisco Muruzabal ${ }^{3,4}$ \\ Gorka Orive ${ }^{3-6}$ \\ Eduardo Anitua ${ }^{3,4}$
}

'University Institute FernándezVega, Ophthalmological Research Foundation, University of Oviedo, Oviedo, Spain; ${ }^{2}$ Quilmes Eye Center, Buenos Aires, Argentina; ${ }^{3}$ University Institute for Regenerative Medicine and Oral Implantology (UIRMI), University of the Basque Country, Eduardo Anitua Foundation, Vitoria, Spain; ${ }^{4}$ Biotechnology Institute (BTI), Vitoria, Spain; ${ }^{5}$ Laboratory of Pharmacy and Pharmaceutical Technology, Faculty of Pharmacy, University of the Basque Country, Vitoria, Spain; ${ }^{6}$ Networking Biomedical Research Center on Bioengineering, Biomaterials and Nanomedicine, CIBER-BBN, Vitoria, Spain

Correspondence: Ronald M Sánchez-Avila Fernández-Vega University Institute, Ophthalmological Research Foundation, Avda Dres Fernández-Vega num 34, Oviedo PC-33012, Spain

$\mathrm{Tel}+34985240141$

Fax +34 985233288

Email ronald.sanchezavila@gmail.com
Purpose: To evaluate the efficacy and safety of plasma rich in growth factors (PRGF) eye drops in patients with glaucoma with secondary ocular surface disorders (OSDs) due to surgeries and topical hypotensive drugs use.

Materials and methods: A retrospective case-series study design was used including six patients (eight eyes) diagnosed with glaucoma who received surgical (nonpenetrating deep sclerectomy and/or trabeculectomy) and medical treatments (hypotensive eye drops) to control intraocular pressure (IOP) and who developed secondary OSDs, unresponsive to conventional treatments. Patients were treated with PRGF eye drops (four times a day). Outcome measures were ocular surface disease index (OSDI), best-corrected visual acuity (BCVA, in logarithm of the minimum angle of resolution), visual analog scale (VAS), frequency and severity of symptoms, and IOP. The safety of the treatment was also evaluated.

Results: Six patients (seven eyes with open-angle glaucoma and one eye with uveitic glaucoma) treated with PRGF eye drops were evaluated. Mean age was 71 years $(\mathrm{SD}=7.2$, range 58-79 years). Five were female and one was male. The mean treatment time was 21.8 weeks ( $\mathrm{SD}=9.0$, range 12-36 weeks). The mean time to reach closure of the corneal ulcer was 14.5 $(\mathrm{SD}=5.5)$ weeks. A statistical significant reduction in OSDI scale (50.6\%), VAS frequency $(53.1 \%)$, VAS severity $(42.0 \%)$, and a $41.8 \%$ improvement in BCVA were observed $(p<0.05)$. IOP also decreased by $16.6 \%(p=0.010)$. Only one of the six patients reported itching in both eyes as an adverse event (AE); however, the patient continued with the PRGF eye drops until the end of therapy; the remaining patients did not report any AEs during the follow-up period. Conclusions: In patients with glaucoma and secondary OSDs refractive to conventional treatments, the treatment with PRGF eye drops could be considered a possible therapeutic option, because it demonstrates an improvement in the signs and symptoms of the ocular surface, as well as a better control of the IOP. This is an initial research work that can open doors for future research to confirm these findings.

Keywords: glaucoma, ocular surface disorders, plasma rich in growth factors, PRGF, plateletrich plasma, PRP

\section{Introduction}

Glaucoma is the second leading cause of blindness in the world, according to the World Health Organization. ${ }^{1}$ In Spain, the prevalence of primary open-angle glaucoma (POAG) has been estimated to be $2.1 \% .^{2}$ There are wide arrays of medical and surgical treatments for POAG including nonpenetrant deep sclerectomy (NPDS) and trabeculectomy. ${ }^{3-5}$ NPDS surgery is indicated in patients diagnosed with glaucoma with elevated intraocular pressure (IOP) after management with 
maximal topical therapy. ${ }^{5}$ The most common complications in patients after these surgeries for glaucoma include bleb leakage, hyphema, flat anterior chamber, inflammation in the anterior chamber, bleb encapsulation, and cataractrelated surgery. ${ }^{6,7}$

The first lines of glaucoma therapeutic treatment include topical eye drops, including several groups of drugs: prostaglandin (PG) analogs, alpha agonists, betablockers, carbonic anhydrase inhibitor, cholinergic, or combined. PG analogs are the most potent topical ocular hypotensors currently in the market..$^{5}$ The maximum IOP reduction in the daylight curve was obtained by latanoprost (31\%), followed by travoprost (28\%), bimatoprost $(26 \%)$, and timolol $(23 \%)$, which all obtained similar results in the daylight curve valley. According to the 2007 International Dry Eye Workshop report, topical glaucoma medications and their preservatives are responsible for a form of extrinsic evaporative dry eye induced by their pathologic side effects on the ocular surface. $^{8}$

The benzalkonium chloride (BAK) preservative associated with the long-term use of topical drugs for glaucoma may induce ocular surface disorders (OSDs), causing a number of symptoms and signs including discomfort, tear film instability, conjunctival inflammation, subconjunctival fibrosis, epithelial apoptosis, and corneal surface impairment. ${ }^{9}$ The mechanisms by which BAK is involved in the induction of OSDs are still being debated, but may potentially result from an especially proinflammatory, toxic, or, more rarely, an allergic etiology.In the treatment of ocular surface pathologies, the so-called PRP (platelet-rich plasma) has been used; clinical efficacy and safety depend on the manufacturing process of each of them; the preparation systems (closed or open), the method of obtaining the blood, the type of anticoagulant, the centrifugation, the activation process, the heating, storage, stability, and dispensing are involved in the manufacturing process. ${ }^{10,11}$ A particular type of PRP is eye drop PRGF (plasma rich in growth factor) manufactured with the Endoret system (BTI Biotechnology Institute, S.L., Miñano, Álava, Spain). This eye drop has approval as a human use product, ${ }^{12}$ and it is manufactured with a closed technique that makes its manufacture safer and more reproducible. It has a standardized manufacturing protocol; calcium chloride is used as a platelet activator, which initiates a greater release of growth factors, ${ }^{13,14}$ and when the PRGF is heated at $56^{\circ} \mathrm{C}$ for 1 hour, the immunoglobulin $\mathrm{E}$ content and complement activity are reduced, and its stability can be maintained up to 6 months. ${ }^{15}$ All these technical advantages have not been demonstrated by other PRP. Additionally, there is ample evidence of the efficacy and safety of the use of PRGF eye drops in pathologies of the ocular surface and cornea ${ }^{16}$.

In the present case-series study report, we evaluate the safety and efficacy of PRGF eye drops, a new blood-based autologous eye drop with significant advantages compared to autologous serum (AS). ${ }^{16}$ The PRGF eye drops consist of a 100\% autologous PRP with no proinflammatory cytokines in their composition. ${ }^{16,17}$ Basic and clinical studies support the use of PRGF eye drops in several disorders of the ocular surface. ${ }^{16-20}$ We show for the first time treatment with PRGF eye drops and clinical evaluation of patients with glaucoma who developed diverse OSDs secondary to the inflammatory mechanism of this pathology and to the use of topical hypotensive drugs.

\section{Materials and methods}

This retrospective case-series study included patients diagnosed with glaucoma who received surgical (non-penetrating deep sclerectomy and or trabeculectomy) and medical treatments (hypotensive eye drops) to control IOP and who developed secondary OSDs unresponsive to conventional treatments.

These patients were treated with PRGF eye drops and were evaluated at the Fernandez-Vega University Institute (Oviedo-Spain) by ophthalmologists between January 2010 and September 2013. All patients included in this study signed informed consent for the use of PRGF eye drops and to have their data used in this study. The Clinical Research Committee of Fernandez-Vega University Institute approved this study. The principles of the Declaration of Helsinki were fulfilled to perform this study.

Included patients had the following conditions: POAG, any secondary glaucoma, age $>18$ years, had previous glaucoma surgeries (NPDS, trabeculectomy), and had developed diverse severe OSDs (dry eye disease [DED], corneal ulcers, and so on) after glaucoma surgery that did not respond (with poor or no response) to conventional treatments (artificial tears, topical antibiotics and steroids, oral antibiotics or antiviral drugs, therapeutic contact lenses, and lacrimal plugs), or AS and/or cyclosporine.

For the diagnosis of DED, patients must meet all the following criteria: 1) Schirmer I-test $<5 \mathrm{~mm}$ (the measurement of tear secretion requires about $5 \mathrm{~min}$, allowing for natural blinking); 2) Tear film breakup time $<5$ seconds; 3) Subjective symptoms of dry eye in the level of severe (as defined in EDE Workshop Committee in 2007). ${ }^{8}$ 4) Lesion on the ocular surface (dry eye syndrome, blepharitis, corneal ulcer, keratitis, and so on). 


\section{PRGF preparation and patients' treatment}

Blood from patients was collected into $9 \mathrm{~mL}$ tubes, after informed consent. Samples were centrifuged at $580 \times \mathrm{g}$ for $8 \mathrm{~min}$ at room temperature in an Endoret System centrifuge (BTI Biotechnology Institute, S.L., Miñano, Álava, Spain). The whole column of PRGF was collected after centrifugation, avoiding the buffy coat that contains the leukocytes, using an Endoret ophthalmology kit (BTI Biotechnology Institute, S.L., Miñano, Álava, Spain). The obtained supernatant was incubated at $37^{\circ} \mathrm{C}$ for $1 \mathrm{~h}$, and then heat treated at $56^{\circ} \mathrm{C}$ for $60 \mathrm{~min}$. The plasma supernatants were filtered, aliquoted, and stored at $-20^{\circ} \mathrm{C}$ until use. All procedures were performed under highly sterile conditions, operating inside a laminar flow hood. The eye drops were then heated to $57^{\circ} \mathrm{C}$ to inactivate the complement (immuno-safe). Before initiating the treatment, the patients were instructed to keep the PRGF eye-drop dispensers at $-20^{\circ} \mathrm{C}$ for a maximum of 3 months; each dispenser was used for 3 consecutive days (the eye drops could be at $8^{\circ} \mathrm{C}$ or ambient temperature).

PRGF eye drops were applied topically (in the conjunctival sac) four times daily for 6 weeks in the affected eye. In case of poor or no initial response, an additional 6 weeks of treatment was administered, up to a maximum of 36 weeks. The treatment with PRGF eye drops did not exclude the use of other concomitant treatments (antibiotic agents, anti-inflammatory, artificial tears, and so on) when considered necessary by clinicians.

\section{Outcome measures}

Both the demographic (gender, age) and clinical variables of patients (systemic diseases, type of glaucoma, hypotensive eye drops, eye diseases, eye surgery, associated treatment, and use of topical corticosteroids) were collected. All necessary data were obtained from patient clinical records.

Treatment response was determined by a combination of clinical examination (slit lamp) and evaluation of ocular surface symptoms using diverse outcome measures: Ocular surface disease index (OSDI), the best-corrected visual acuity (BCVA) using Snellen optotype (conversion to logarithmic scale of the minimum angle of resolution [LogMAR]), visual analog scale (VAS, frequency and severity of symptoms), and IOP were also determined. All measures were taken before starting (baseline), and after finishing treatment with PRGF eye drops. The following times were recorded: duration of treatment with PRGF eye drops, follow-up after treatment, and time to reach closure of the corneal ulcer.

The evaluation of ocular surface symptoms was performed using the Spanish version of the OSDI scale that includes 12 questions, ${ }^{21}$ and estimates the severity of dry-eye symptoms in a range from 0 to 100 , and with the VAS, which is a 100 -point scale in which $0=$ no discomfort and $100=$ maximal discomfort (dryness, burning/stinging, photophobia, foreign body sensation, blurred vision, itching, and pain), both in the frequency and severity of symptoms. IOP was determined with the Perkins tonometer, based on the same principles as the Goldmann applanation tonometry. A safety assessment was also performed recording and evaluating any adverse event (AE) or complication that occurred during the patient's follow-up period.

\section{Statistical analysis}

Data were analyzed using absolute and relative frequency distributions for qualitative variables, and mean values and SDs for quantitative variables. Patients' treatment response was analyzed comparing outcomes measures' mean values between baseline and after PRGF treatment using the nonparametric Wilcoxon statistical test. The level of statistical significance was set at $p<0.05$. The statistical software package SPSS v19.0 for Windows (SPSS Inc., Chicago, IL, USA) was used for all statistical analyses.

\section{Results}

Data from six patients (seven eyes with open-angle glaucoma and one eye with uveitic glaucoma) treated with PRGF eye drops were recorded and evaluated. Mean age of patients was 71 years ( $\mathrm{SD}=7.2$, range $58-79$ years). Five were female and one patient was male. Patients had different previous associated eye diseases, and received diverse surgery types and topical hypotensive drugs therapy for glaucoma. Table 1 summarizes the clinical situation of the patients. Patients received between 12 and 36 weeks of treatment with PRGF eye drops. Mean treatment time was 21.8 weeks $(\mathrm{SD}=9.0)$. The mean time of follow-up after treatment was 12.3 weeks $(\mathrm{SD}=4.5)$. The mean time to reach closure of the corneal ulcer was $14.5(\mathrm{SD}=5.5)$ weeks.

Results of primary outcome measures before and after PRGF eye-drop treatment are summarized in Figures 1 and 2. A significant reduction in the OSDI scale was observed from a baseline value of $50.6(\mathrm{SD}=37.6)$ to a final post-treatment value of $21.0(\mathrm{SD}=11.5)$. The latter represents a total reduction of $50.6 \%$, which was statistically significant $(p=0.027$; Figure 1A). The BCVA was reduced from a baseline value of $0.59(\mathrm{SD}=0.43)$ to a final post-treatment value of 0.33 $(\mathrm{SD}=0.31$ ), showing an improvement of $41.84 \%$ in BCVA $(p \leq 0.0326$; Figure 1B). 
Table I Demographic and clinical data of six included patients with glaucoma

\begin{tabular}{|c|c|c|c|c|c|c|c|c|}
\hline $\begin{array}{l}\text { Patient } \\
\text { number }\end{array}$ & Age & Gender & $\begin{array}{l}\text { Glaucoma } \\
\text { type }\end{array}$ & $\begin{array}{l}\text { Previous } \\
\text { hypotensive drugs }\end{array}$ & $\begin{array}{l}\text { Previous ophthalmic } \\
\text { surgeries }\end{array}$ & $\begin{array}{l}\text { Other ocular } \\
\text { pathologies }\end{array}$ & $\begin{array}{l}\text { Secondary } \\
\text { OSDs }\end{array}$ & $\begin{array}{l}\text { PRGF } \\
\text { weeks }\end{array}$ \\
\hline 1 & 76 & Female & Open angle & Apraclonidine (BE) & Cataract surgery $(\mathrm{BE})$ & $\begin{array}{l}\text { AMD (BE) } \\
\text { Posterior blephatritis (BE) }\end{array}$ & $\begin{array}{l}\text { DED/corneal } \\
\text { ulcer (BE) }\end{array}$ & 18 \\
\hline 2 & 79 & Female & Open angle & $\begin{array}{l}\text { Timolol/bimatoprost/ } \\
\text { dorzolamide/ } \\
\text { pilocarpine (LE) }\end{array}$ & Ahmed valve (LE) & $\begin{array}{l}\text { Retinal detachment (LE) } \\
\text { Corneal dystrophy aphakia } \\
\text { (RE) }\end{array}$ & $\begin{array}{l}\text { Corneal ulcer } \\
\text { (LE) }\end{array}$ & 30 \\
\hline 3 & 66 & Female & Open angle & $\begin{array}{l}\text { Timolol/latanoprost/ } \\
\text { travoprost/ } \\
\text { brinzolamide (LE) }\end{array}$ & $\begin{array}{l}\text { Cataract (BE) } \\
\text { Vitrectomy with silicon oil } \\
\text { Amniotic membrane (LE) }\end{array}$ & $\begin{array}{l}\text { Amblyopia (LE) } \\
\text { Retinal detachment (LE) }\end{array}$ & $\begin{array}{l}\text { Corneal ulcer } \\
\text { (LE) }\end{array}$ & 18 \\
\hline 4 & 65 & Female & Open angle & $\begin{array}{l}\text { Timolol/bimatoprost/ } \\
\text { dorzolamide/ } \\
\text { brinzolamide (LE) }\end{array}$ & $\begin{array}{l}\text { Vitrectomy and scleral } \\
\text { buckling (RE) } \\
\text { Cataract surgery (BE) }\end{array}$ & $\begin{array}{l}\text { Macular hole (LE) } \\
\text { Amblyopia (LE) } \\
\text { AMD (BE) }\end{array}$ & $\begin{array}{l}\text { Corneal ulcer } \\
\text { (LE) }\end{array}$ & 36 \\
\hline 5 & 58 & Female & Uveitic & $\begin{array}{l}\text { Timolol/travoprost/ } \\
\text { brinzolamide/ } \\
\text { brimonidine (RE) }\end{array}$ & $\begin{array}{l}\text { Ahmed valve (RE) } \\
\text { Conjunctival flap (RE) } \\
\text { Cataract surgery (RE) }\end{array}$ & $\begin{array}{l}\text { Necrotizing scleritis and } \\
\text { uveitis (RE) } \\
\text { Central trophic ulcer (RE) }\end{array}$ & $\begin{array}{l}\text { Corneal ulcer } \\
\text { (RE) }\end{array}$ & 30 \\
\hline 6 & 74 & Male & Open angle & $\begin{array}{l}\text { Travaprost/ } \\
\text { brinzolamide (BE) }\end{array}$ & $\begin{array}{l}\text { Nonpenetrating deep } \\
\text { sclerectomy (BE) }\end{array}$ & AMD (BE) & $\begin{array}{l}\text { DED/corneal } \\
\text { ulcer (BE) }\end{array}$ & 12 \\
\hline
\end{tabular}

Abbreviations: AMD, age-related macular degeneration; BE, both eyes; DED, dry eye disease; LE, left eye; OSD, ocular surface disorders; PRGF, plasma rich in growth factors; RE, right eye.
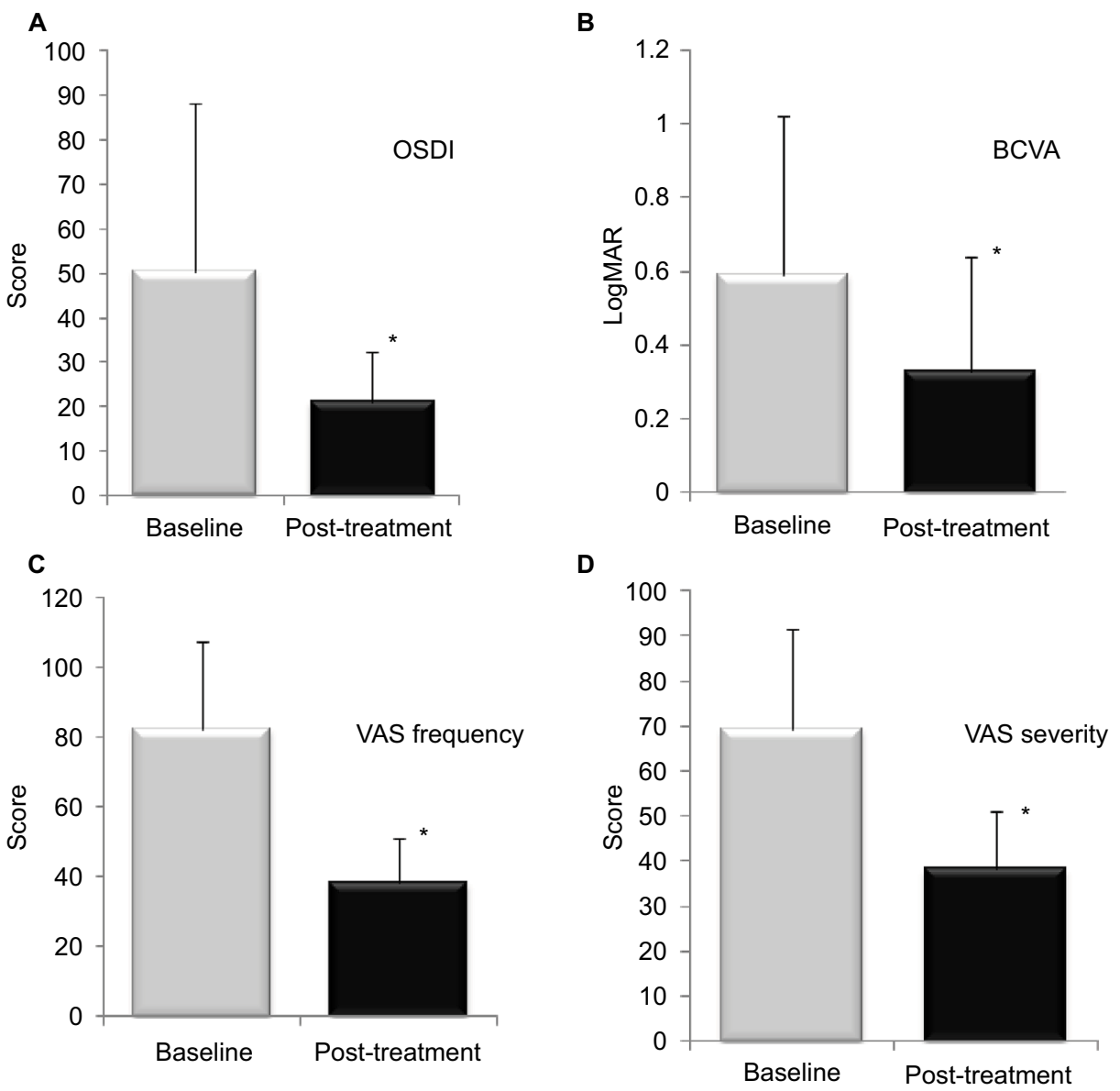

Figure I Bar graphs showing the different outcome measures before and after treatment with PRGF (OSDI [A], BCVA [B], and VAS severity-frequency of symptoms [C-D]).

Note: ${ }^{*} p<0.05$.

Abbreviations: BCVA, best-corrected visual acuity; OSDI, ocular surface disease index; PRGF, plasma rich in growth factors; VAS, visual analog scale. 


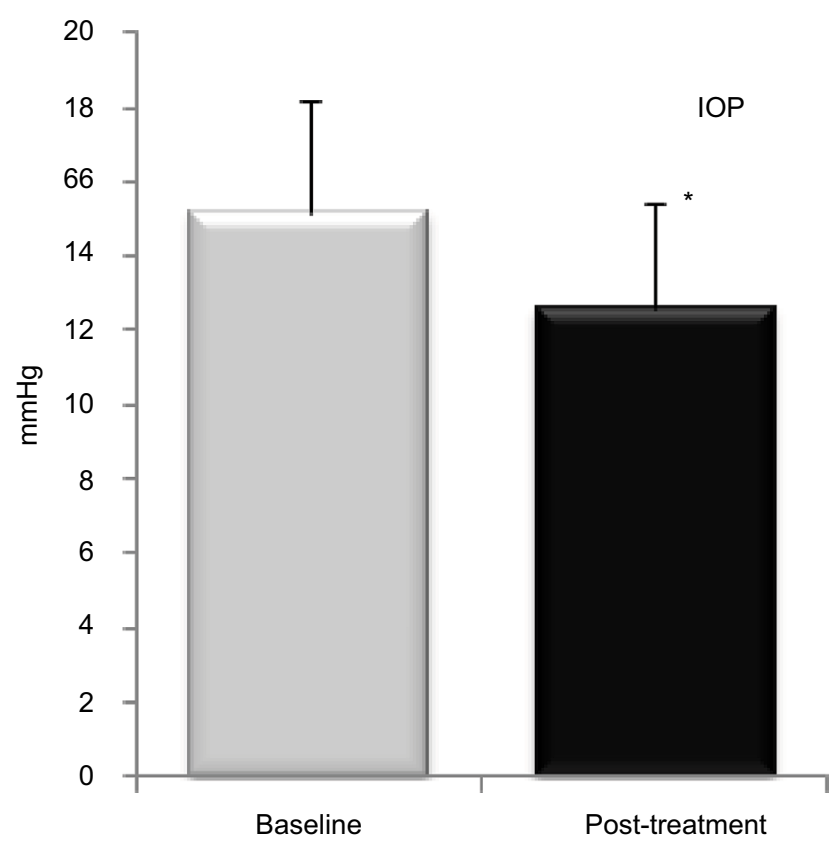

Figure 2 Bar graph showing IOP before and after PRGF treatment. Note: ${ }^{*} p<0.05$.

Abbreviations: IOP, intraocular pressure; PRGF, plasma rich in growth factors.

Regarding the ocular symptoms (discomfort, dryness, burning/stinging, photophobia, foreign body sensation, blurred vision, itching, and pain) measured by the VAS score in frequency of symptoms, a significant decrease was measured ranging from a baseline value of $82.5(\mathrm{SD}=25.3)$ to a final post-treatment value of $38.3(\mathrm{SD}=12.9)$. This represented a reduction of $53.1 \%$ which was statistically significant ( $p=0.026$; Figure 1C). Finally, the VAS score of severity of symptoms resulted in a relevant and significant decrease of $42.0 \%$, going from a baseline value of $69.2(\mathrm{SD}=22.5)$ to a final post-treatment value of $38.3(\mathrm{SD}=12.9)$, which was statistically significant ( $p=0.027$; Figure 1D). Regarding IOP, a reduction of $16.6 \%$ was observed after treatment, going from a baseline value of $15.13(\mathrm{SD}=3.0)$ to a final post-treatment value of $12.6(\mathrm{SD}=2.8)$, which was statistically significant $(p=0.010)$. Figures 1 and 2 show mean values before and after PRGF eye-drop treatment.

Regarding safety assessment, only one of the six patients reported itching in both eyes as an AE but continued with PRGF treatment. The remaining patients did not report any AEs during the follow-up period. The use of corticosteroids, antibiotics, or other additional treatments was not necessary during follow-up in patients treated with PRGF eye drops.

Figures 3-5 show eye examination with slit lamp of three of the included patients with glaucoma and associated OSDs,

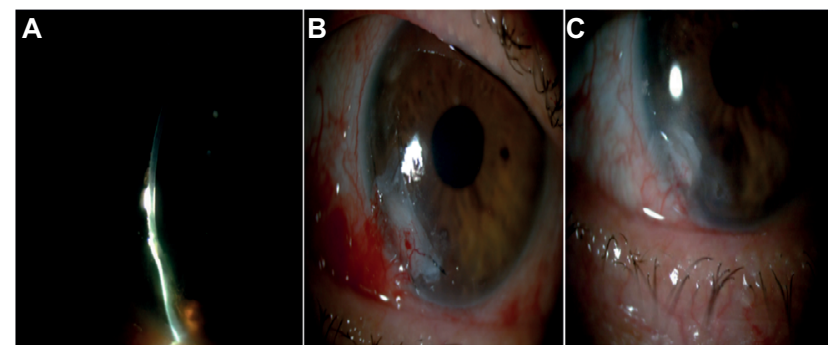

Figure 3 Photographs showing one of the cases (patient \#3) with an epithelial and stromal ulcer defect in the left eye.

Notes: (A) Baseline situation before treatment with PRGF eye drops showing the corneal ulcer that reaches deep stroma, with consequent risk of corneal perforation. (B) During PRGF treatment, with a therapeutic contact lens 2 weeks after a second amniotic membrane transplant. (C) Final clinical situation I month after finishing PRGF treatment observing corneal defect closure and corneal regeneration in process.

Abbreviation: PRGF, plasma rich in growth factors.
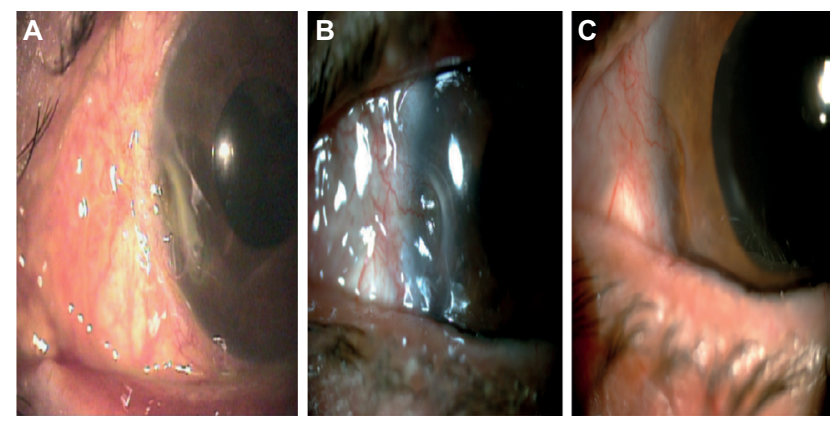

Figure $4 \mathrm{~A}$ sequence of three photographs showing one of the treated cases (patient \#4) with an epithelial and stromal defect in the left eye with new vessels, and an additional limbic insufficiency.

Notes: (A, B) Baseline situation before initiating PRGF treatment with an important stromal defect and ocular surface inflammation and associated neovascularization. (C) Final clinical situation after PRGF treatment showing the favorable closure of the epithelial and stromal defect, inflammation reduction, and less vascularization. Abbreviation: PRGF, plasma rich in growth factors.
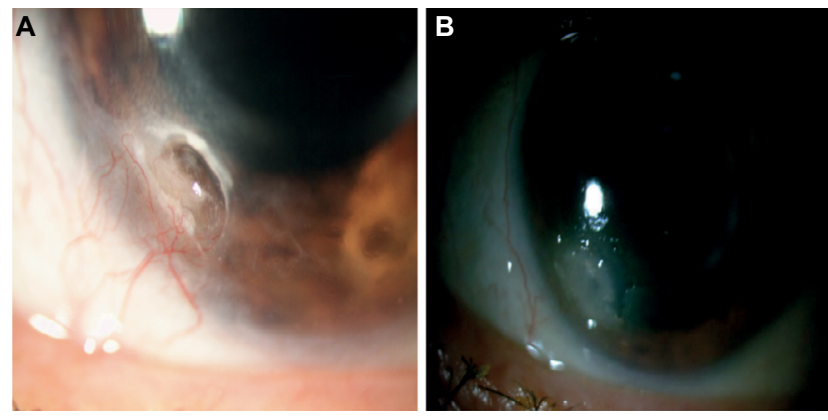

Figure 5 Photographs (patient \# 5) with deep corneal ulcer, associated neovessels and risk of corneal perforation.

Notes: (A) Basal situation: deep corneal ulcer, thick neovessels, and risk of perforation. (B) Four weeks of PRGF treatment: closure of corneal ulcer, minor inflammation, and decrease of neovessels. Corneal regeneration continues to progress.

Abbreviation: PRGF, plasma rich in growth factors. 
where the clinical improvement after treatment with PRGF eye drops was clinically significant.

\section{Discussion}

This retrospective clinical study involved six patients with glaucoma and secondary OSDs treated with PRGF eye drops. To our knowledge, this is the first study in the literature that evaluates a blood-derived treatment based on plasma and platelets in patients with glaucoma, used to treat secondary OSDs.

Patients suffering from glaucoma usually have ocular surface alterations associated with the use of topical eye drops. Most of these topical drugs have preservatives that stimulate the inflammatory mechanisms that exacerbate glaucoma, leading to ocular surface disease. Topical agents and in particular preservatives such as BAK, which induce the expression of inflammatory cell markers at the ocular surface, may provoke epithelial cell damage, cell death by apoptosis, and a decrease in goblet cell density. ${ }^{22}$ Recently, it was reported that the use of preservatives was associated with a lower expression of MUC5AC and the lowest MUC5AC levels were associated with the highest ICAM-1 and HLADR levels. ${ }^{23}$ This negative correlation suggested inflammation as a possible basis for the decreased mucin expression, in addition to any direct effect of BAK on goblet cells themselves. $^{8,22}$ Pisella et al, in an unmasked study of 4,107 glaucoma patients, found that the frequency of ocular surface changes was twice as high in those receiving preserved drops as in those receiving unpreserved drops, and the frequency of signs and symptoms was dose-related. ${ }^{24}$

Results reported herein support that in glaucoma patients with secondary OSDs, treatment with PRGF eye drops could be considered a possible therapeutic option to improve associated signs and symptoms and to reduce IOP. There are several potential explanations for these effects. Firstly, PRGF eye drops contain a cocktail of trophic agents. For example, they contain large amounts of epidermal growth factor, which may be responsible for the increased proliferation and migration activity, promoting accelerated wound healing time in corneal injuries. ${ }^{25-27}$ In addition, PRGF eye drops also contain fibroblast growth factor, insulinlike growth factor-1, and platelet-derived growth factor (PDGF), with critical roles in promoting proliferation and migration of stromal fibroblasts in ocular surface tissues; the PRGF eye drops also have nerve growth factor with its neurotrophic properties in the cornea. ${ }^{17}$ Secondly, several studies have supported that PRGF eye drops reduce scar formation because of the balance of PDGF/transforming growth factor- $\beta 1$ (TGF- $\beta 1$ ) in their composition. ${ }^{16}$ Thirdly, PRGF eye drops exert potent anti-inflammatory effects. ${ }^{17} \mathrm{~A}$ better control on inflammation could contribute to a higher treatment adherence in patients with glaucoma. Last but not least, PRGF eye drops have shown clinical efficacy in patients with moderate-to-severe dry eye, diverse epithelial defects, and corneal ulcers, ${ }^{18,19,10,28-30}$ the efficacy and safety of PRGF eye drops in the treatment of neurotrophic keratitis have also been demonstrated. ${ }^{31}$

TGF- $\beta$ because of its pleiotropic properties contributes to normal cellular physiologic processes, and also to the development of ophthalmologic pathologies such as glaucoma or corneal scars. ${ }^{27,32}$ It is known that the increased activity of TGF- $\beta$ leads to the increase of deposits in the extracellular matrix of the trabecular tissue, with increase in the outflow resistance of the aqueous humor, and the consequent elevation of intraocular pressure; anti-TGF- $\beta$ drugs are being developed as possible therapeutic options for glaucoma. ${ }^{32,33}$ In vitro and in vivo studies have shown that PRGF eye drops can modulate the activity of TGF- $\beta$, decreasing tissue fibrosis and favoring cell regeneration, ${ }^{16,15}$ these mechanisms could explain the decrease in intraocular pressure.

When interpreting the results from the present study, some limitations should be considered. One important issue is that results come from a retrospective study and in a small number of patients. This type of study has less validity than prospective clinical studies, because of the issues of selection bias and confounding factors. Further prospective and controlled clinical studies should be performed to corroborate the therapeutic potential efficacy of PRGF eye drops in glaucoma patients with secondary OSDs.

\section{Conclusion}

In this study, patients with glaucoma and secondary OSDs refractive to conventional treatments showed a significant global clinical improvement after treatment with PRGF eye drops, in signs and symptoms. Although more clinical studies are needed, treatment with PRGF eye drops could be considered a possible therapeutic option in glaucoma patients with secondary OSDs, to improve both clinical signs and symptoms of associated pathology and also for reducing IOP.

\section{Acknowledgments}

The authors would like to thank Virginia Cuadrado for her support with English grammar. This study received funding from the Ministry of Economy and Competitiveness of the Spanish Government, within the project denominated SURFEYE (reference RTC-2014-2375-1). 


\section{Disclosure}

The authors declare the following competing financial interest(s): EA is the Scientific Director of BTI Biotechnology Institute, GO and FM are scientists at BTI Biotechnology Institute, a dental implant company that investigates in the fields of oral implantology and PRGF-Endoret technology. The authors report no other conflicts of interest in this work.

\section{References}

1. Pascolini D, Mariotti SP. Global estimates of visual impairment: 2010. Br J Ophthalmol. 2012;96(5):614-618.

2. Anton A, Andrada MT, Mujica V, Calle MA, Portela J, Mayo A. Prevalence of primary open-angle glaucoma in a Spanish population: the Segovia study. J Glaucoma. 2004;13(5):371-376.

3. Chiselita D. Non-penetrating deep sclerectomy versus trabeculectomy in primary open-angle glaucoma surgery. Eye (Lond). 2001;15(Pt 2):197-201.

4. Mermoud A, Schnyder CC. Nonpenetrating filtering surgery in glaucoma. Curr Opin Ophthalmol. 2000;11(2):151-157.

5. Lachkar Y, Hamard P. Nonpenetrating filtering surgery. Curr Opin Ophthalmol. 2002;13(2):110-115.

6. Lachkar Y, Neverauskiene J, Jeanteur-Lunel MN, et al. Nonpenetrating deep sclerectomy: a 6-year retrospective study. Eur J Ophthalmol. 2004;14(1):26-36.

7. Baudouin C, Labbe A, Liang H, Pauly A, Brignole-Baudouin F. Preservatives in eyedrops: the good, the bad and the ugly. Prog Retin Eye Res. 2010;29(4):312-334.

8. Michael AL, Christophe B, Jules B, et al. The definition and classification of dry eye disease: report of the definition and classification subcommittee of the International Dry Eye WorkShop (2007). Ocul Surf. 2007;5(2): $75-92$.

9. Monaco G, Cacioppo V, Consonni D, Troiano P. Effects of osmoprotection on symptoms, ocular surface damage, and tear film modifications caused by glaucoma therapy. Eur J Ophthalmol. 2011;21(37): 243-250.

10. Alio JL, Colecha JR, Pastor S, Rodriguez A, Artola A. Symptomatic dry eye treatment with autologous platelet-rich plasma. Ophthalmic Res. 2007;39(3):124-129.

11. Alio JL, Rodriguez AE, Martinez LM, Rio AL. Autologous fibrin membrane combined with solid platelet-rich plasma in the management of perforated corneal ulcers: a pilot study. JAMA Ophthalmol. 2013;131(6):745-751.

12. Anitua E, Prado R, Orive G. Closing regulatory gaps : new ground rules for platelet-rich plasma. Trends Biotechnol. 2015;33(9):492-495.

13. Freire V, Andollo N, Etxebarria J, Duran JA, Morales MC. In vitro effects of three blood derivatives on human corneal epithelial cells. Invest Ophthalmol Vis Sci. 2012;53(9):5571-5578.

14. Freire V, Andollo N, Etxebarria J, Hernaez-Moya R, Duran JA, Morales MC. Corneal wound healing promoted by 3 blood derivatives: an in vitro and in vivo comparative study. Cornea. 2014;33(6):614-620.

15. Riestra AC, Alonso-Herreros JM, Merayo-Lloves J. [Plasma rico en plaquetas en superficie ocular]. Arch Soc Esp Oftalmol. 2016;91(10):475490. Spanish.

International Medical Case Reports Journal

\section{Publish your work in this journal}

The International Medical Case Reports Journal is an international, peer-reviewed open-access journal publishing original case reports from all medical specialties. Previously unpublished medical posters are also accepted relating to any area of clinical or preclinical science. Submissions should not normally exceed 2,000 words or
16. Anitua E, Muruzabal F, Tayebba A, et al. Autologous serum and plasma rich in growth factors in ophthalmology: preclinical and clinical studies. Acta Ophthalmol. 2015;93(8):e605-e614.

17. Anitua E, Muruzabal F, de la Fuente M, Merayo J, Duran J, Orive G. Plasma rich in growth factors for the treatment of ocular surface diseases. Curr Eye Res. 2016;41(7):875-882.

18. Merayo-Lloves J, Sanchez-Avila RM, Riestra AC, et al. Safety and efficacy of autologous plasma rich in growth factors eye drops for the treatment of evaporative dry eye. Ophthalmic Res. 2016;56(2):68-73.

19. Merayo-Lloves J, Sanchez RM, Riestra AC, et al. Autologous plasma rich in growth factors eyedrops in refractory cases of ocular surface disorders. Ophthalmic Res. 2015;55(2):53-61.

20. Anitua E, Alonso R, Girbau C, Aguirre JJ, Muruzabal F, Orive G. Antibacterial effect of plasma rich in growth factors $\left(\mathrm{PRGF}^{\circledR}\right.$-Endoret $\left.{ }^{\mathbb{\Xi}}\right)$ against Staphylococcus aureus and Staphylococcus epidermidis strains. Clin Exp Dermatol. 2012;37(6):652-657.

21. Schiffman RM, Christianson MD, Jacobsen G, Hirsch JD, Reis BL. Reliability and validity of the Ocular Surface Disease Index. Arch Ophthalmol. 2000;118(5):615-621.

22. Onizuka N, Uematsu M, Kusano M, Sasaki H, Suzuma K, Kitaoka $\mathrm{T}$. Influence of different additives and their concentrations on corneal toxicity and antimicrobial effect of benzalkonium chloride. Cornea. 2014;33(5):521-526.

23. Baudouin C, Pisella PJ, Fillacier K, et al. Ocular surface inflammatory changes induced by topical antiglaucoma drugs: human and animal studies. Ophthalmology. 1999;106(3):556-563.

24. Pisella PJ, Pouliquen P, Baudouin C. Prevalence of ocular symptoms and signs with preserved and preservative free glaucoma medication. Br J Ophthalmol. 2002;86(4):418-423.

25. Freire V, Andollo N, Etxebarria J, Durán JA, Morales MC. In vitro effects of three blood derivatives on human corneal epithelial cells. Invest Ophthalmol Vis Sci. 2012;53(9):5571-5578.

26. Freire V, Andollo N, Etxebarria J, Hernáez-Moya R, Durán JA, Morales MC. Corneal wound healing promoted by 3 blood derivatives: an in vitro and in vivo comparative study. Cornea. 2014;33(6):614-620.

27. Anitua E, Muruzabal F, Alcalde I, Merayo-Lloves J, Orive G. Plasma rich in growth factors (PRGF-Endoret) stimulates corneal wound healing and reduces haze formation after PRK surgery. Exp Eye Res. 2013;115:153-161.

28. Lopez-Plandolit S, Morales MC, Freire V, Etxebarria J, Duran JA. Plasma rich in growth factors as a therapeutic agent for persistent corneal epithelial defects. Cornea. 2010;29(8):843-848.

29. Lopez-Plandolit S, Morales MC, Freire V, Grau AE, Duran JA. Efficacy of plasma rich in growth factors for the treatment of dry eye. Cornea. 2011;30(12):1312-1317.

30. Alio JL, Pastor S, Ruiz-Colecha J, Rodriguez A, Artola A. Treatment of ocular surface syndrome after LASIK with autologous platelet-rich plasma. J Refract Surg. 2007;23(6):617-619.

31. Sanchez-Avila RM, Merayo-Lloves J, Riestra AC, et al. Treatment of patients with neurotrophic keratitis stages 2 and 3 with plasma rich in growth factors (PRGF-Endoret) eye-drops. Int Ophthalmol. Epub 2017 Jun 15.

32. Agarwal R, Agarwal P. Future target molecules in antiglaucoma therapy: tgf-Beta may have a role to play. Ophthalmic Res. 2010;43(1):1-10.

33. Wang J, Harris A, Prendes MA, et al. Targeting transforming growth factor-beta signaling in primary open-angle glaucoma. J Glaucoma. 2017;26(4):390-395. 